These short summaries are taken from a range of other evidence-based journals and publicatons

\section{Effect of printed education materials alone is at best small and of uncertain clinical significance in changing the behaviour of health care professionals}

Evidence-based Health Policy and Management. March 1998

Freemantle N, Harvey E L, Wolf F, Grimshaw I M, Grilli R, Bero L A. Printed educational materials to improve the behaviour of health care professionals and patients outcomes. In Bero L, Grilli R, Grimshaw J, Oxman A, (eds) Collaboration on Effective professional Practice Module of the Cochrane Database of Systematic Reviews. The Cochrane Collaboration. Oxford: Update Software, 1998.

This review was produced by the Cochrane Collaboration Group looking at effective professional practice. The review did show that printed educational materials do have some small benefits. However, none of the various outcomes measuring professional behaviour or changes in patient outcome were statistically significant. Additional interventions were shown to have mixed results with educational outreach and opinions leaders likely to have more effect. There were no economic evaluations of the studies included in the review so the benefit of these additional interventions in terms of cost is uncertain.

\section{Longer patient visits and better communication with patients were associated with a lower incidence of malpractice claims}

\section{Evidence-based Health Policy and Management. June 1998}

Levinsio W, Roter D L, Mullooly J P, Dull V T, Frankel R M. Physicianpatient communication: the relationship with malpractice claims among primary care physicians and surgeons. JAMA 1997 277: 553-559.

This cross-sectional study compared audiotapes of consultations of primary care physicians and surgeons in Colorado and Oregon USA in 1993. Physicians were grouped according to claims history, speciality and years in practice. The study suggests that good communication with patients and longer visits by primary care physicians are correlated with fewer claims.

The authors acknowledged the study design limitations but this carefully conducted piece of research draws to attention the importance of adequate time for the doctor-patients consultation. It also stresses the need to include communication skills training when updating. In a period when complaints are encouraged it should remind us of the dearth of UK based research in this field of negligence claims and clinical complaints.

\section{Health Education can change the diet of children}

Evidence-based Health Policy and Management. December 1998

Perry C L, Bishop D B, Taylor $\mathrm{G}$ et al. Changing fruit and vegetable consumption among children: the Five-a-day Power Plus Program in St Paul, Minnesota. Am J Pub Hith

1998: $88: 603-609$

This randomised trial took place in 20 schools in urban Minneapolis St Paul and involved 1750 students with $82 \%$ being seen one year following the intervention. It is one of a series from the US program, 'Five-a-Day for better health', launched in 1991. There was a significant increase in lunchtime fruit and vegetable consumption. The proportion of total calorie intake attributed to fruit and vegetable also increased. The study demonstrates that health promotion can work but it also demonstrates that they need to be multifaceted. Here they are involving teachers, school curriculum, parents' school food providers and local industry. Despite the comprehensive nature of the intervention the impact was greater for fruit than vegetables and on girls more than boys. This reinforces the complexity of behaviour change and the need for multiple interventions that complement each other. 